\title{
Functional Characterization and Proteomic Analysis of Porcine Deltacoronavirus Accessory Protein NS7
}

\author{
Subin Choi and Changhee Lee ${ }^{*}$ \\ Animal Virology Laboratory, School of Life Sciences, BK21 PLUS KNU Creative BioResearch Group, Kyungpook National University, Daegu \\ 41566, Republic of Korea
}

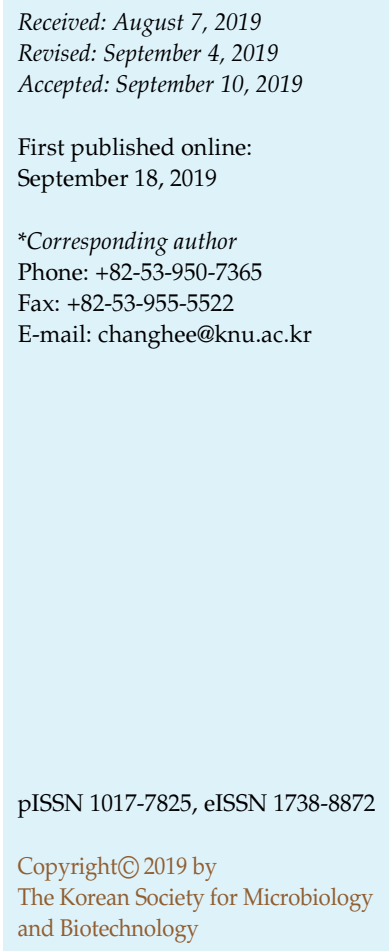

Porcine deltacoronavirus $(\mathrm{PDCoV})$ is an emerging swine enteric coronavirus that causes diarrhea in neonatal piglets. Like other coronaviruses, PDCoV encodes at least three accessory or species-specific proteins; however, the biological roles of these proteins in PDCoV replication remain undetermined. As a first step toward understanding the biology of the PDCoV accessory proteins, we established a stable porcine cell line constitutively expressing the PDCoV NS7 protein in order to investigate the functional characteristics of NS7 for viral replication. Confocal microscopy and subcellular fractionation revealed that the NS7 protein was extensively distributed in the mitochondria. Proteomic analysis was then conducted to assess the expression dynamics of the host proteins in the PDCoV NS7-expressing cells. Highresolution two-dimensional gel electrophoresis initially identified 48 protein spots which were differentially expressed in the presence of NS7. Seven of these spots, including two upregulated and five down-regulated protein spots, showed statistically significant alterations, and were selected for subsequent protein identification. The affected cellular proteins identified in this study were classified into functional groups involved in various cellular processes such as cytoskeleton networks and cell communication, metabolism, and protein biosynthesis. A substantial down-regulation of $\alpha$-actinin- 4 was confirmed in NS7-expressing and PDCoV-infected cells. These proteomic data will provide insights into the understanding of specific cellular responses to the accessory protein during PDCoV infection.

Keywords: PDCoV, accessory protein, NS7, mitochondrial localization, proteomics, ACTN4

\section{Introduction}

Porcine deltacoronavirus (PDCoV) is a newly discovered entero-tropic swine coronavirus which was first detected in Hong Kong, China in 2012 [1]. In early 2014, outbreaks of PDCoV in the US state of Ohio were announced, and then this novel coronavirus rapidly spread to multiple other US states [2-5]. Numerous independent investigations demonstrated that PDCoV can cause severe enteric lesions and clinical diarrhea in neonatal and gnotobiotic pigs in the absence of other etiologic agents [6-9]. Since then, PDCoV has been identified in several Asian pig-raising countries including South Korea [10], mainland China [11], and Thailand [12]. A recent survey revealed a relatively high prevalence of PDCoV across South Korea since its emergence in the country [13]. This study found that monoinfection with PDCoV, and coinfection with PDCoV and porcine epidemic diarrhea virus (PEDV), are most common in domestic pig herds, posing significant financial concerns and attracting particular attention [13].

PDCoV is a large, enveloped virus that belongs to the genus Deltacoronavirus within the family Coronaviridae of the order Nidovirales [1, 14]. The virus possesses a singlestranded, positive-sense RNA genome of approximately 25.4-kb with a 5' cap and a 3' polyadenylated tail. It has the smallest genome among the known porcine coronaviruses $[1,14]$. The PDCoV genome consists of six canonical coronaviral genes in the following conserved order: $5^{\prime}$ untranslated region (UTR)-open reading frame (ORF) 1aORF1b-S-E-M-N-3' UTR. The first two large ORFs, 1a and 
$1 \mathrm{~b}$, encompass the $5^{\prime}$-proximal two-thirds of the genome, and encode two overlapping replicase polyproteins via a -1 ribosomal frameshift. These polyproteins undergo autoproteolysis by viral proteases to eventually produce 15 processing nonstructural proteins (nsp2-16). The 3'-proximal last third of the genome codes for the four structural proteins, spike $(\mathrm{S})$, envelope $(\mathrm{E})$, membrane $(\mathrm{M})$, and nucleocapsid $(\mathrm{N})$, as well as at least three accessory proteins, nonstructural gene 6 (NS6), NS7, and NS7a [1-3, 10, 15-17].

A variable number of accessory or species-specific genes are interspersed widely between or within the structural protein genes of coronavirus $[18,19]$. In the PDCoV genome, there are three putative accessory genes, NS6, NS7, and NS7a. NS6 is predicted to be located between M and N, while NS7 is located within $\mathrm{N}$ in an alternative ORF encoding a 200-amino acid polypeptide [1, 16, 17]. The remaining gene, NS7a, is a novel accessory protein with 100 amino acid residues identical to the 3 '-end of NS7 [17]. Although it is acknowledged that coronavirus accessory proteins are not essential for viral multiplication in vitro $[20,21]$, they have been shown to serve functions in immune modulation and viral pathogenesis in vivo [2226]. Thus, the field of coronavirus accessory proteins has come to be of considerable interest, because of their potential to provide insights into the viral life cycle. However, despite their significance in coronavirology, little information on the putative accessory proteins of PDCoV, particularly NS7, has been reported to date.

In the present study, alterations in cellular gene expression caused by the NS7 protein were evaluated as a first step towards understanding the biological role of NS7 in PDCoV replication. To accomplish this task, stable porcine-origin cell lines constitutively expressing the PDCoV NS7 protein were generated and characterized. Changes in the expression patterns of various cellular proteins in the NS7 protein-expressing porcine cells compared with those in control cells were examined using proteomic analysis at different time points. Our proteomic data provide novel information for better understanding of the properties and functions of the NS7 protein during PDCoV infection.

\section{Materials and Methods}

\section{Cells, Virus, and Antibodies}

HEK-293T and HeLa cells were cultured in Dulbecco's modified Eagle medium (DMEM) with high glucose (Invitrogen, USA) with $10 \%$ fetal bovine serum (FBS; Invitrogen) and antibiotic-antimycotic solutions (100x; Invitrogen). PK-15 and PK-15-Neo [27] cells were grown in RPMI 1640 medium (Invitrogen) supplemented with $10 \%$ FBS and antibiotic-antimycotic solutions $(100 \times)$ in the absence or presence of $200 \mu \mathrm{g} / \mathrm{ml}$ G418 (Invitrogen), respectively. ST cells were cultured in alpha minimum essential medium $(\alpha-$ MEM; Invitrogen) with 5\% FBS and antibiotic-antimycotic solutions $(100 \times)$. The cells were maintained at $37^{\circ} \mathrm{C}$ in an atmosphere of humidified air containing 5\% $\mathrm{CO}_{2}$. PDCoV strain KNU16-07 was propagated in ST cells in virus growth medium [ $\alpha$-MEM supplemented with antibiotic-antimycotic solutions, $10 \mathrm{mM}$ HEPES (Invitrogen), and $5 \mu \mathrm{g} / \mathrm{ml}$ trypsin (USB, USA)] without FBS, as previously described [28]. The PDCoV N protein-specific monoclonal antibody (MAb) was described previously [28]. Rabbit anti-6× histidine (His) tag MAb and mouse anti-voltagedependent anion channel (VDAC) MAb were purchased from Cell Signaling Technologies (USA). Mouse anti-myc MAb and Alexa Fluor 488-conjugated goat anti-mouse (rabbit) IgG and Alexa Fluor 594-conjugated goat anti-rabbit IgG secondary antibodies were obtained from Invitrogen. Rabbit monoclonal antibodies against Calreticulin, GM130, and LMAN1 were purchased from Abcam (Cambridge, UK). The $\alpha$-tubulin antibody was purchased from Sigma-Aldrich (USA). Mouse monoclonal antibodies against $\beta$-actin and $\alpha$-actinin- 4 and horseradish peroxidase (HRP)conjugated goat anti-mouse (rabbit) IgG secondary antibodies were obtained from Santa Cruz Biotechnology (USA).

\section{Construction of the PDCoV NS7 Plasmid}

DNA manipulation and cloning were performed according to standard procedures [29]. Escherichia coli strain DH5 $\alpha$ (RBC Bioscience, Taiwan) was used as the host for general cloning. The full-length NS7 gene was amplified from the PDCoV KNU14-04 strain [10] with the following primer pair: KNU14-04-NS7-Fwd (5'-GCCGGTCGACATGGAGTTCCGC-3') and KNU14-04-NS7Rev (5'-GCCGGGATCCGAGCCATGATGC-3'), where underlines indicate the SalI and BamHI restriction enzyme sites, respectively. The PCR amplicon was initially inserted into the pBudCE4.1 vector (Invitrogen) that contains a $m y c$ epitope and six repetitive histidine codons, and the resulting plasmid pBud-PDCoV-NS7 was verified by nucleotide sequencing. Because the PDCoV genome contains a newly discovered accessory gene, NS7a, within the NS7 gene in an identical reading frame, the presence of NS7a could affect our functional studies of the PDCoV NS7 protein. To prevent any such adverse effects, the translation initiation codon of the NS7a ORF was modified to disrupt its expression using pBud-PDCoV-NS7. To accomplish this, PCR-directed mutagenesis was conducted to change the ATG start codon of NS7a to ATA at genomic nucleotide positions 24,396 to 24,398 , using pBudPDCoV-NS7 as a template, with the following primers for the G24397A mutation: NS7a-KO-Fwd (5'-CCAACCGGAGATaGC CCAGCTCAAG-3') and NS7a-KO-Rev (5'-CTTGAGCTGGGCtAT CTCCGGTTGG-3'), where lowercase letters indicate the mutated nucleotides. Since methionine is encoded only by the single codon ATG, the translationally non-silent mutation was adopted by changing it to isoleucine, which is the closest residue in 
mutational and physico chemical distances [30]. The resulting plasmid, pBud-PDCoV-NS7 ${ }^{\text {NS7aKO }}$, was verified by nucleotide sequencing. A fragment of PDCoV NS7 ${ }^{\mathrm{NS7} \text { KKO }}$ cDNA that was prepared from $\mathrm{pBud}-\mathrm{PDCoV}-\mathrm{NS} 7^{\mathrm{NS7} a \mathrm{KO}}$ was then subcloned into the pFB-Neo retroviral vector (Stratagene, USA) using the SalI and EcoRI restriction sites to construct the PDCoV NS7 gene expression plasmid pFB-Neo-PDCoV-NS7-myc/His, which produces the recombinant NS7 protein.

\section{Generation of Stable PK-15 Cell Lines Expressing the PDCoV NS7 Protein}

The retrovirus gene transfer system (Stratagene) was used to generate cell lines constitutively expressing the recombinant PDCoV NS7 gene or an empty vector only, as described elsewhere [27, 31-33]. Antibiotic-resistant continuous cell clones were analyzed using RT-PCR to determine the presence of the fulllength NS7 gene, and the positive clones (PK-PDCoV-NS7) were amplified for subsequent experiments.

\section{Immunofluorescence Assay (IFA) and Confocal Microscopy}

PK-PDCoV-NS7 cells were grown on microscope coverslips placed in 6-well tissue culture plates. At $48 \mathrm{~h}$ post-seeding, the cells were fixed with $4 \%$ paraformaldehyde for $10 \mathrm{~min}$ at room temperature (RT) and permeabilized with $0.2 \%$ Triton X-100 in PBS at RT for $10 \mathrm{~min}$. The cells were blocked using $1 \%$ bovine serum albumin (BSA) in PBS for $30 \mathrm{~min}$ at RT and then incubated with the anti-His tag antibody for $2 \mathrm{~h}$. After washing five times in PBS, the cells were incubated for $1 \mathrm{~h}$ at RT with a goat anti-rabbit secondary antibody conjugated with Alexa Fluor 488, followed by counterstaining with 4',6-diamidino-2-phenylindole (DAPI; SigmaAldrich). The coverslips were mounted on glass microscope slides in mounting buffer and the stained cells were visualized using a fluorescence Leica DM IL LED microscope (Leica, Wetzlar, Germany). For the study of colocalization, HeLa cells on microscope coverslips placed in 6-well plates were transfected with a plasmid encoding NS7 for $48 \mathrm{~h}$ and subjected to co-staining with the following primary antibodies: mouse anti-myc tag antibody and rabbit anti-Calreticulin, anti-GM130, or antiLMAN1 antibody. The cells were incubated with a mixture of Alexa Fluor 488-conjugated anti-mouse and Alexa Fluor 594conjugated anti-rabbit secondary antibodies, followed by DAPI counterstaining. In addition, MitoTracker Red CMXRos (200 nM; Invitrogen) was added to the transfected HeLa and PK-PDCoVNS7 cells under indicated conditions as described previously [34]. The cells were then stained with anti-myc tag antibody as described above. Fluorescent images for co-staining were obtained using a Confocal Laser Scanning microscope (Carl Zeiss, Germany).

\section{Fluorescence-Activated Cell Sorting (FACS) Analysis}

The expression of NS7 in PK-PDCoV-NS7 cells was analyzed using flow cytometry. The cells were trypsinized at $48 \mathrm{~h}$ postseeding and centrifuged at $250 \times g$ (Hanil Centrifuge FLETA 5) for $5 \mathrm{~min}$. The cell pellet was washed with cold washing buffer $(1 \%$
BSA and $0.1 \%$ sodium azide in PBS), and $10^{6}$ cells were resuspended in $1 \%$ formaldehyde solution in cold wash buffer for fixation at $4^{\circ} \mathrm{C}$ in the dark for $30 \mathrm{~min}$ followed by centrifugation and incubation of the pellet in $0.2 \%$ Triton $\mathrm{X}-100$ in PBS at $37^{\circ} \mathrm{C}$ for $15 \mathrm{~min}$ for permeabilization. After centrifugation, the cell pellet was resuspended in a solution of the primary anti-His tag antibody or normal rabbit $\operatorname{IgG}$ (Invitrogen) and the mixture was incubated at $4^{\circ} \mathrm{C}$ for $30 \mathrm{~min}$. The cells were washed and allowed to react with an Alexa Fluor 488-conjugated anti-rabbit IgG secondary antibody at $4^{\circ} \mathrm{C}$ for $30 \mathrm{~min}$ in the dark. The stained cells were washed again and analyzed using a BD FACSAria III flow cytometer (BD Biosciences, USA).

\section{Cell Proliferation Assay}

The growth properties of cells expressing PDCoV NS7 protein and control PK-Neo cells were determined by a 3-(4,5dimethylthiazol-2-yl)-2,5-diphenyltetrazolium bromide (MTT) assay (Sigma-Aldrich) to detect cell viability, as previously described [27, 34]. All MTT assays were performed in triplicate.

\section{Subcellular Fractionation and Western Blot Analysis}

Whole-cell lysates were prepared from PK-PDCoV-NS7 and PDCoV-infected ST cells grown in 6-well tissue culture plates at the time points indicated, using lysis buffer as described previously [34]. For subcellular fractionation, PK-PDCoV-NS7 cells were fractionated using a Mitochondria/Cytosol Fractionation Kit (BioVision, USA) according to the manufacturer's manuals. The total protein concentrations in the supernatants were determined using a BCA protein assay (Pierce, USA). The cell lysates were mixed with $4 \times$ NuPAGE sample buffer (Invitrogen) and boiled at $70^{\circ} \mathrm{C}$ for $10 \mathrm{~min}$. Equal amounts of total protein were separated in a NuPAGE 4-12\% Gradient Bis-Tris Gel (Invitrogen) under reducing conditions and electrotransferred onto an Immobilon-P membrane (Millipore, USA). The membranes were subsequently blocked with $3 \%$ powdered skim milk (BD Biosciences) in TBS (10 mM Tris- $\mathrm{HCl}$ [pH 8.0], $150 \mathrm{mM} \mathrm{NaCl}$ ) with $0.05 \%$ Tween-20 (TBST) at $4^{\circ} \mathrm{C}$ for $2 \mathrm{~h}$ and reacted at $4^{\circ} \mathrm{C}$ overnight with the primary antibodies. The blots were then incubated with corresponding secondary HRP-labeled antibodies at a dilution of 1:5,000 for $2 \mathrm{~h}$ at $4^{\circ} \mathrm{C}$. Finally, the proteins were visualized using enhanced chemiluminescence (ECL) reagents (GE Healthcare, USA) according to the instructions of the manufacturer. To analyze the expression kinetics of cellular proteins in PK-PDCoVNS7 or PDCoV-infected cells, the band densities of each protein were quantified using a computer densitometry with the Wright Cell Imaging Facility (WCIF) version of the ImageJ software package (http://www.uhnresearch.ca/facilities/wcif/imagej/), based on the density value relative to the corresponding housekeeping gene.

Two-Dimensional Gel Electrophoresis (2DE) and Image Analysis

Protein samples for proteomic analysis were prepared as described previously [27] and stored at $-80^{\circ} \mathrm{C}$ until use. 2DE was 
performed using commercial IPG dry strips ( $\mathrm{pH} 4-10,24 \mathrm{~cm}$; Genomine Inc., Korea) for the first-dimensional separation (isoelectric focusing; IEF) and sodium dodecyl sulfatepolyacrylamide gel electrophoresis (SDS-PAGE) for the second dimension, as previously described [27]. The 2D gels were stained using the silver staining method as described previously, with some modifications [35]. To compensate for the variability of 2DE, three independent experiments were conducted to facilitate statistical analysis.

The stained gels were imaged using Dyversity, a highresolution 2D gel CCD image analyzer, (Syngene, USA), and quantitative analysis of the digitized gel images was carried out using the PDQuest software (version 7.0, Bio-Rad, USA) according to the protocols provided by the manufacturer. Data from three independent 2DE experiments for each sample were statistically analyzed. The quantitative data from each protein spot were normalized based on the total valid spot intensity for each gel. Only protein spots that showed significant differential expression $(p<0.05)$ with $\mathrm{a} \pm 2$-fold consistent change in the expression level in comparison with the control sample were selected for mass spectrometry (MS) analysis.

\section{Protein Identification by Peptide Mass Fingerprinting (PMF)}

Each selected protein spot was excised manually from the silver-stained gels and was enzymatically digested in-gel using modified porcine trypsin (Sequencing Grade; Promega, USA) as previously described [27, 36]. MALDI-TOF analysis was performed using a Microflex LRF 20 instrument (Bruker Daltonics, USA) as described in $[27,37]$. The search program MASCOT from Matrix Science (http://www.matrixscience.com/) was used for protein identification by PMF. The following parameters were used for the database search: trypsin as the cleaving enzyme, a maximum of one missed cleavage, iodoacetamide (Cys) as a complete modification, oxidation (Met) as a partial modification, monoisotopic masses, and a mass tolerance of $\pm 0.1 \mathrm{Da}$. The PMF acceptance criterion was probability scoring.

\section{Quantitative Real-Time RT-PCR}

Total RNA was extracted from the lysates of PK-PDCoV-NS7 cells at 12 and $36 \mathrm{~h}$ post-seeding using the TRIzol Reagent (Invitrogen) and was treated with DNase I (TaKaRa, Japan) according to the manufacturer's protocols. The concentrations of the extracted RNAs were measured using a NanoVue spectrophotometer (GE Healthcare). Quantitative real-time RTPCR was performed using a Thermal Cycler Dice Real-Time System (TaKaRa) with gene-specific primer sets as described previously [38]. The sequence information of all the primers was listed in Table 1. The RNA levels of cellular genes were normalized relative to porcine $\beta$-actin mRNA, and the relative quantities (RQ) of mRNA accumulation were calculated using the $2^{-\Delta \Lambda C t}$ method [39]. To detect alterations in cellular mRNA levels in the presence of the PDCoV NS7 protein, the relative fold change of each cellular gene was calculated with the comparison to PKPDCoV-NS7 and control PK-Neo cells.

\section{Statistical Analysis}

All values are expressed as the mean \pm standard deviation of the mean (SDM). Statistical analyses were performed using Student's $t$-test. $P$-values of less than 0.05 were considered to be statistically significant.

\section{Results}

\section{Generation and Characterization of Stable Porcine- Origin Cell Lines Expressing the PDCoV NS7 Accessory Protein}

Although several aspects of the interactions between the PDCoV and its host have been studied, alterations of cellular protein expression in response to the accessory protein remain poorly understood. In the current study, the PDCoV NS7 protein was chosen for proteomic analysis, and specific host cellular responses were evaluated. NS7 is not only a representative accessory protein of PDCoV, but also potentially plays multiple indispensable roles in completing viral infection in vivo. Sublines of PK-15 cells, which stably expressed recombinant PDCoV NS7 under

Table 1. The primers used for real-time RT-PCR in this study.

\begin{tabular}{ll}
\hline \multicolumn{1}{c}{ Target for RT-PCR } & \multicolumn{1}{c}{ Primer sequence $\left(5^{\prime}->3^{\prime}\right)$} \\
\hline Alpha-actinin-4 & Forward: GGCATCAGCCAAGAGCAGAT \\
& Reverse: CTGATGAGGCAGGCCTTGAA \\
Cytoskeletal beta actin & Forward: ACCACTGGCATCGTGATGGA \\
& Reverse: ATGAGGTAGTCGGTCAGGTC \\
Carbamoyl-phosphate synthase & Forward: ACGTCAGCCTGCTTTGAACCT \\
40 ribosomal protein S12-like & Reverse: GCCATGACCTCTCCTACGCT \\
& Forward: GCTTGCATCCAACTGTGATGAG \\
Porcine $\beta$-actin & Reverse: GAGGCCTACCCATTCTCCTAA \\
& Forward: GACCACCTTCAACTCGATCA \\
121 bp & Reverse: GTGTTGGCGTAGAGGTCCTT \\
\hline
\end{tabular}


A

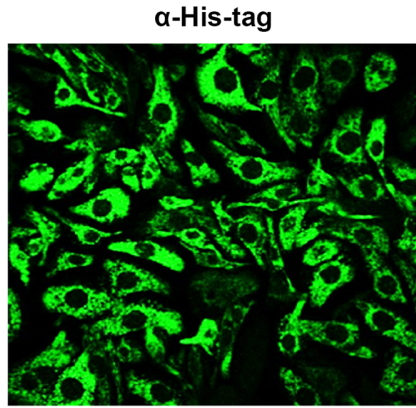

B

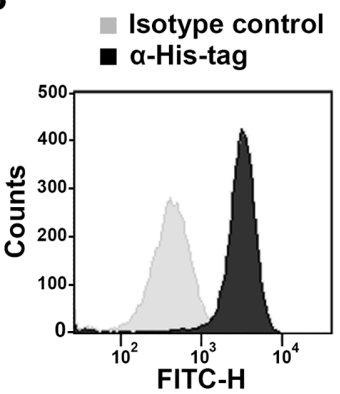

C
DAPI

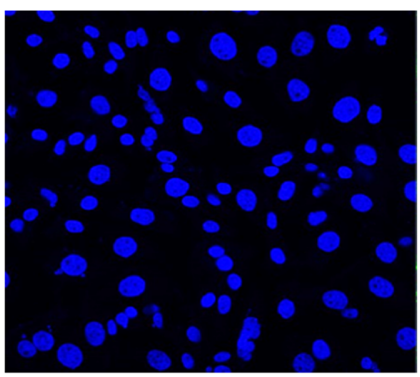

kDa

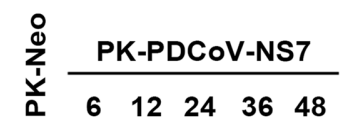

35
25

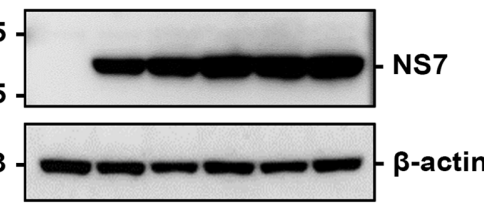

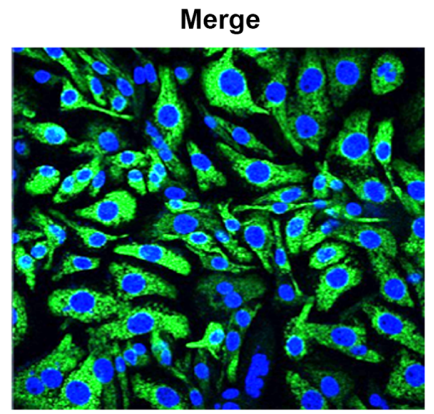

D 600 - PK-Neo

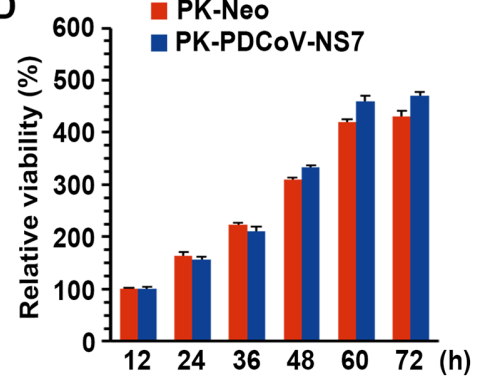

Fig. 1. Constitutive expression of the NS7 protein in PK-PDCoV-NS7 cells.

(A) Immunofluorescence assay of the PDCoV NS7 protein. PK-PDCoV-NS7 cells grown in a 6-well tissue culture plate were fixed with $4 \%$ formaldehyde at the time points indicated and incubated with His tag-specific antibody followed by goat anti-mouse secondary antibody conjugated with Alexa green (left panel). The cells were then counterstained with DAPI (middle panel) and examined using a fluorescence microscope at 200x magnification. (B) Intracellular expression of PDCoV NS7. One million cells were harvested at $48 \mathrm{~h}$ post-seeding and incubated with anti-His tag antibody (black histogram) or an isotype control (gray histogram) and analyzed using flow cytometry. (C) Immunoblot analysis of the NS7 protein. PK-PDCoV-NS7 cells were grown in a 6-well tissue culture plate at $4 \times 10^{5}$ cells $/$ well for $6,12,24,36$, and $48 \mathrm{~h}$. Cell lysates were prepared at the time points indicated and subjected to western blot analysis with anti-His tag antibody to determine the expression levels of the NS7 protein (upper panel). The blot was also reacted with mouse MAb against $\beta$-actin to confirm equal protein loading (lower panel). (D) Growth kinetics of the stable PDCoV NS7 protein-expressing cells. Cell proliferation was measured at the indicated times by the MTT assay. Values are representative of the mean of three independent experiments and error bars denote standard deviations.

the control of a retroviral long-terminal-repeat promoter, were established. Ten cell clones were collected and subjected to RT-PCR and western blotting to confirm the NS7 gene expression at the mRNA and protein levels (data not shown). Assuming a relatively minor expression of NS7 as an accessory protein in PDCoV-infected cells, one PK-PDCoV-NS7 cell clone that constitutively expressed a modest level of NS7 was selected for subsequent studies on the basis of the western blotting results.

To characterize the PK-PDCoV-NS7 cells, we assessed the intracellular expression levels of NS7 using IFA, FACS analysis and western blotting. As shown in Fig. 1A, specific cell staining was clearly evident when PK-PDCoV-NS7 cells were treated with anti-His tag antibody, confirming a constant expression level of the NS7 protein. The majority of the cells consistently exhibited specific fluorescent signals, indicating a homogenous population of cells in terms of NS7 expression (Fig. 1B). Time-course western blot analysis showed that the PK-PDCoV-NS7 cells stably expressed and accumulated steady intensities of an around $25 \mathrm{kDa}$ recombinant NS7 protein. This weight is larger than the predicted molecular weight of approximately $22 \mathrm{kDa}$, which was estimated based upon putative post-translational modifications and the presence of C-terminal myc and histidine tags (Fig. 1C). The overall growth kinetics of PDCoV NS7-expressing PK cells were found to be comparable to those of the parental PK-Neo cells, indicating that PDCoV NS7 expression had no effect on cell proliferation (Fig. 1D).

We next examined the precise subcellular localization of the recombinant NS7 protein expressed in PK-PDCoV-NS7 cells using immunofluorescence confocal microscopy. Due to the commercial unavailability of organelle marker antibodies reacting with swine validated in IFA, we initially carried out transient transfection of HeLa cells with the plasmid pBud-PDCoV-NS7 ${ }^{\text {NS7aKO }}$ (Fig. 2A). The transfected cells were stained with mouse anti-myc antibody 
A

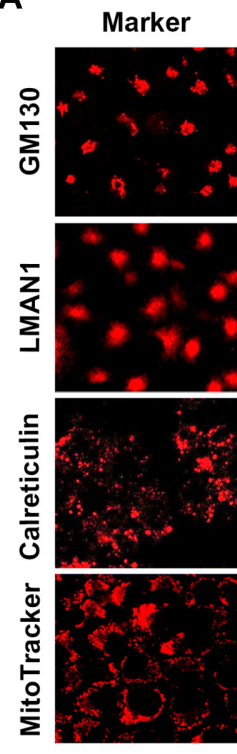

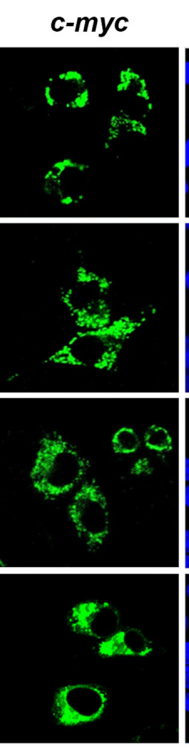

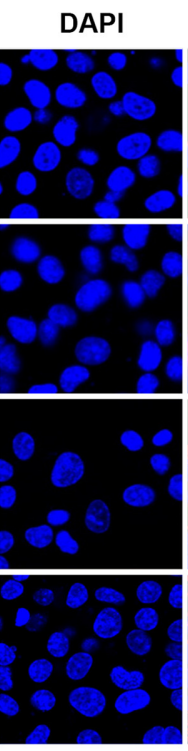

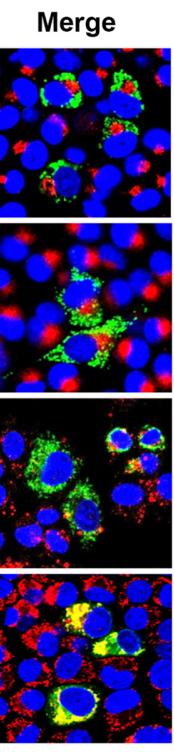

B
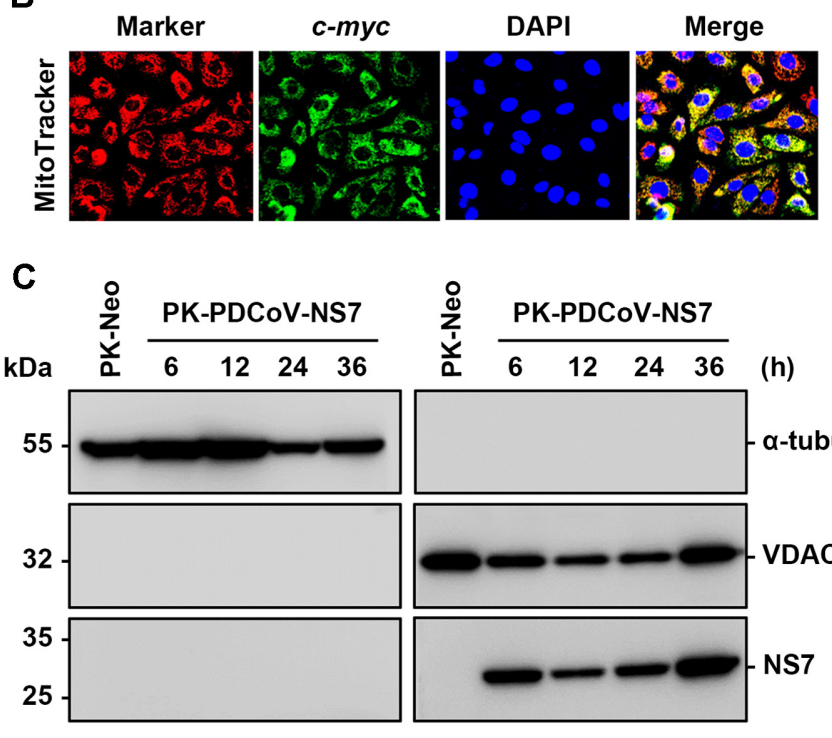

Cytosol

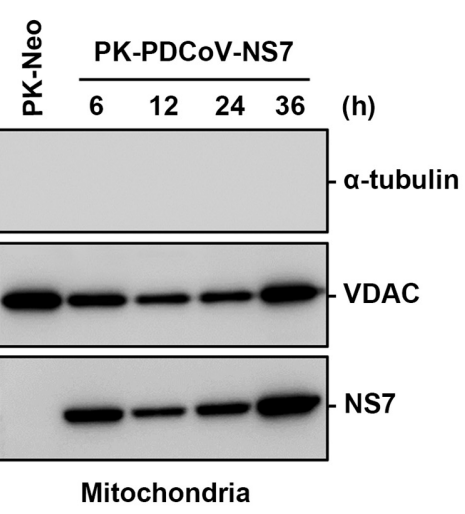

Fig. 2. Mitochondrial localization of the PDCoV NS7 protein expressed in PK-PDCoV-NS7 cells.

(A) Subcellular localization of NS7 in cells transiently expressing (A) and stably expressing (B) PDCoV NS7. HeLa cells were fixed at $48 \mathrm{~h}$ posttransfection and co-stained with anti-myc tag and each organelle marker antibody, followed by incubation with a mixture of Alexa Fluor 594 (red)conjugated goat anti-rabbit and 488 (green)-conjugated goat anti-mouse secondary antibodies. In addition, transfected HeLa or PK-PDCoV-NS7 cells were labeled with MitoTracker Red CMXRos, fixed, and incubated with anti-myc tag MAb followed by Alexa green-conjugated goat antimouse secondary antibody. The cells were then counterstained with DAPI and visualized using a confocal fluorescence microscope at 400x magnification. (C) Cytoplasmic and mitochondrial fractionations of PK cells expressing PDCoV NS7. Each cytosolic and mitochondrial fraction was prepared from PK-PDCoV-NS7 cells at the time points indicated post-seeding and subjected to western blot analysis with the antibody specific for $\alpha$-tubulin as a cytosolic protein marker (top panel), VDAC as a mitochondrial protein marker (middle panel), or His-tag (bottom panel).

and rabbit antibodies against either the endoplasmic reticulum (ER) marker Calreticulin, the Golgi apparatus marker GM130, the ER-Golgi intermediate compartment (ERGIC) marker LMAN1, or a mitochondrial tracking reagent. The NS7 protein was observed to be localized primarily in the mitochondria; it co-stained only with a mitochondrial-specific marker, and not with other organelle markers (Fig. 2A). The mitochondrial localization of PDCoV NS7 was confirmed in PK-PDCoV-NS7 cells (Fig. 2B). The staining pattern in PK-PDCoV-NS7 cells was found to be predominantly cytoplasmic, and virtually all cells expressing NS7 showed distinct fluorescent signals in the mitochondria. These observations were further verified by subcellular fractionation and western blotting, which detected NS7 exclusively in mitochondrial extracts (Fig. 2C). These data demonstrated that the accessory NS7 protein is mostly distributed in the mitochondria and cytoplasm, suggesting that its unique subcellular localization is important to its function(s) in PDCoV infection.

\section{DE Analysis of Porcine Cells Constitutively Expressing the PDCoV NS7 Protein}

Cellular proteins were extracted from the parental PKNeo cells and PK-PDCoV-NS7 cells and subjected to 2DE analysis in order to compare the host protein expression profiles. To reduce the variability inherent in gel electrophoresis, three independent 2DE analyses of cellular extracts from control and NS7-expressing PK cells were performed, and spot intensity data from the triplicate gels were used for statistical analysis. On average, 1,230 \pm 33 protein spots were resolved by $2 \mathrm{DE}$ within a $\mathrm{pH}$ gradient of 4 to 10 and were visualized using silver staining; the molecular weights of the spots ranged from 10 to $200 \mathrm{kDa}$. Fig. 3A shows representative images of $2 \mathrm{DE}$ gels from control PK cells (top panels) and NS7-expressing PK cells (middle and bottom panels). A total of 48 protein spots were found to be differentially expressed in PK-PDCoVNS7 cells when compared with control PK-Neo cells. On the basis of the statistical comparison, only those spots that 
A

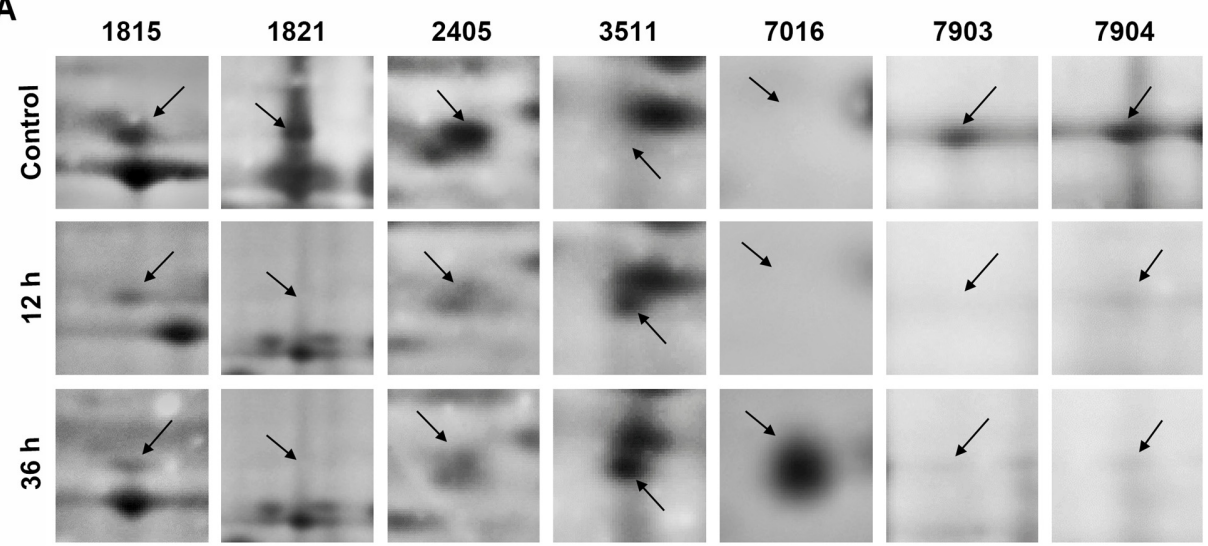

B
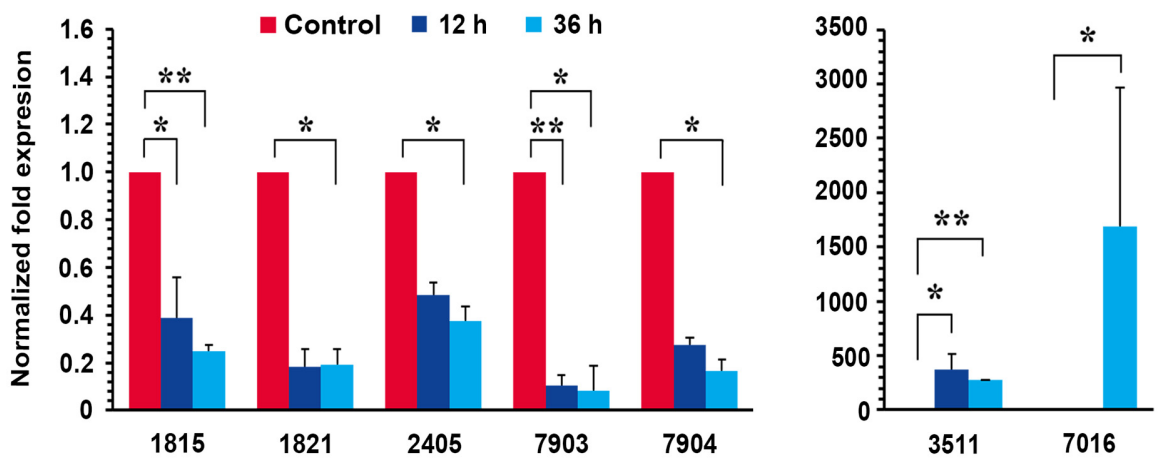

Fig. 3. Representative gel images showing spots that displayed significantly differential expression.

(A) The magnified pictures represent the proteomic analysis of control PK-Neo (top panel) and PK-PDCoV-NS7 cells (middle and bottom panels) and exhibited differentially regulated proteins identified in NS7 gene-expressing cells. Four-digit numbers at the top represent individual spot identifications. (B) The quantity of each spot was normalized based on the total valid spot intensity for each gel, and the relative fold change of each spot was then calculated between control PK-Neo and PK-PDCoV-NS7 cells. Data representing three independent 2DE experiments for each sample were statistically analyzed and are presented as mean \pm SDM. ${ }^{*} p=0.001$ to $0.05 ;{ }^{* *} p<0.001$.

showed statistically significant alterations in expression levels between PK-PDCoV-NS7 cells and the control cells were chosen for further protein identification.

\section{Identification of Differentially Expressed Proteins}

Seven protein spots with statistically significant changes, including two up-regulated and five down-regulated protein spots (Fig. 3B), were picked and subjected to MALDI-TOF analysis. Using combined PMF and database searching, the identities of five out of the seven proteins, including two spots representing identical proteins, were successfully determined. Information on all these proteins in PK-PDCoV-NS7 cells with their protein scores and sequence coverage is summarized in Table 2. To better understand the implications of the cellular responses to the PDCoV NS7 protein, we further categorized these proteins according to biological process, using the Gene Ontology database, as described previously [40]. These proteins showing altered expression were associated with cellular functions including metabolic processes, protein synthesis, and cytoskeleton networks.

Since changes in cellular protein expression may be attributed to alterations in the corresponding mRNA levels, transcriptional changes for all of the identified proteins were tested using real-time RT-PCR, to confirm the results of the proteomic analysis (Fig. 4). The altered expression patterns of some identified proteins were somewhat erratic compared with those in the real-time RTPCR results, showing modest increases or reductions in mRNA levels. However, two spots, predicted to be $\alpha$ actinin-4 (ACTN4) and carbamoyl phosphate synthase 1 (CPS1), were significantly down-regulated in both mRNA and protein levels. 
Table 2. List of differentially expressed cellular proteins in PDCoV NS7-expressing PK cells.

\begin{tabular}{|c|c|c|c|c|c|c|c|}
\hline $\begin{array}{l}\text { Spot } \\
\text { no. }\end{array}$ & Protein name & Accession no. & $\begin{array}{l}\text { MW } \\
(\mathrm{kDa})\end{array}$ & $\mathrm{pI}$ & $\begin{array}{l}\text { Protein } \\
\text { score }\end{array}$ & $\begin{array}{c}\text { Sequence } \\
\text { coverage (\%) }\end{array}$ & Function \\
\hline \multicolumn{8}{|c|}{ Up-regulated protein } \\
\hline 7016 & $40 \mathrm{~S}$ ribosomal protein S12-like & gi| 795560028 & 13.6 & 6.47 & 184 & 80 & Protein synthesis \\
\hline \multicolumn{8}{|c|}{ Down-regulated proteins } \\
\hline 1815 & Alpha-actinin-4 isoform & gi $\mid 545830727$ & 106.30 & 4.68 & 284 & 37 & Cytoskeleton organization \\
\hline 1821 & Cytoskeletal beta actin & gi| 45269029 & 112.6 & 4.77 & 131 & 46 & Cytoskeleton organization \\
\hline 7903 & Carbamoyl-phosphate synthase, mitochondrial & gi $\mid 1191845107$ & 127.12 & 7.08 & 201 & 16 & Metabolic process \\
\hline 7904 & Carbamoyl-phosphate synthase, mitochondrial & gi $\mid 1191845107$ & 127.17 & 7.20 & 244 & 22 & Metabolic process \\
\hline
\end{tabular}

\section{Differential Expression of ACTN4 in Response to the PDCoV NS7 Protein}

The proteomic data identifying potential host proteins that underwent dynamic alterations in their expression under the influence of PDCoV NS7 were further investigated. Since no commercial antibodies reacting with porcine CPS1 are available, the down-regulated ACTN4 was selected for subsequent time-course western blot analysis. Total cellular lysates were prepared from PKPDCoV-NS7 cells at various time points, and the expression kinetics of this cytoskeleton protein were compared between control and NS7 protein-containing extracts. Lowered

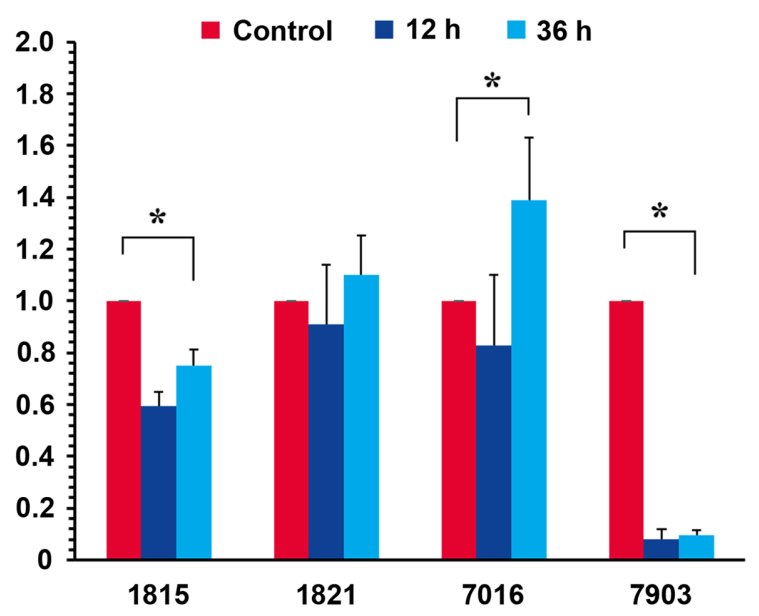

Fig. 4. Transcriptional alteration of identified cellular genes in PK-PDCoV-NS7 cells.

The mRNA level of each gene was assessed using quantitative realtime RT-PCR and normalized to that of porcine $\beta$-actin. Relative quantities (RQ) of mRNA accumulation were evaluated using the 2 ${ }^{\triangle \mathrm{CCt}}$ method, and the relative fold change of each gene was calculated between control PK-Neo and PK-PDCoV-NS7 cells. Results are expressed as the mean values of three independent experiments in duplicate and error bars represent the mean \pm SDM. ${ }^{*} p=0.001$ to 0.05 ; ${ }^{* *} p<0.001$. production of ACTN4 was first evident in NS7-expressing cells as early as at $6 \mathrm{~h}$ post-seeding in comparison with production in non-NS7-expressing cells, and lasted for a longer time in PK-PDCoV-NS7 cells than in control cells, indicating that the reduced expression is dependent upon the presence of the NS7 protein (Fig. 5A). This phenomenon was also observed in cells infected with PDCoV. As shown in Fig. 5B, the expression of ACTN4 was dramatically diminished at 6 and $12 \mathrm{~h}$ post-infection (hpi) in PDCoVinfected cells, and its level reverted to that observed in non-infected cells at 18 hpi. IFA data also revealed that, in comparison with mock-infection, PDCoV infection resulted in a significant decrease in ACTN4-positive cells (Fig. 5C). These results were consistent with those of the proteomic analysis and real-time RT-PCR, indicating that the synthesis of ACTN4 is negatively modulated in response to expression of the NS7 protein of PDCoV.

\section{Discussion}

Viruses have to infect the host cell and hijack its replication machinery to obtain the cellular biosynthetic mechanism and energy supplies needed for their replication and production. At the same time, infection of cells also triggers numerous antiviral responses to neutralize the invading viruses. However, viruses utilize many different strategies to evade host defenses in order to ensure that they successfully replicate and spread, leading to dynamic alterations in host cell gene transcription. Proteomic analysis has been widely adopted to evaluate host protein responses to viral infection or viral protein expression, and to gain understanding of how modified gene expression affects viral replication and pathogenesis [27, 33, 41-46]. Although coronavirus accessory proteins are dispensable for virus replication in vitro, considerable information about their expression, intracellular localization and function of accessory proteins from several different 
A

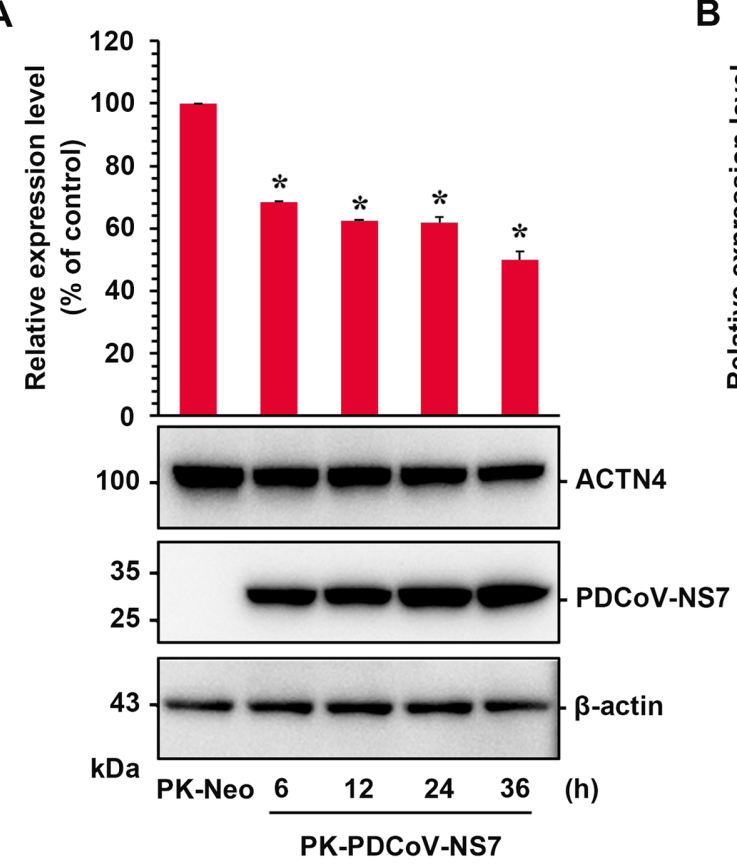

C

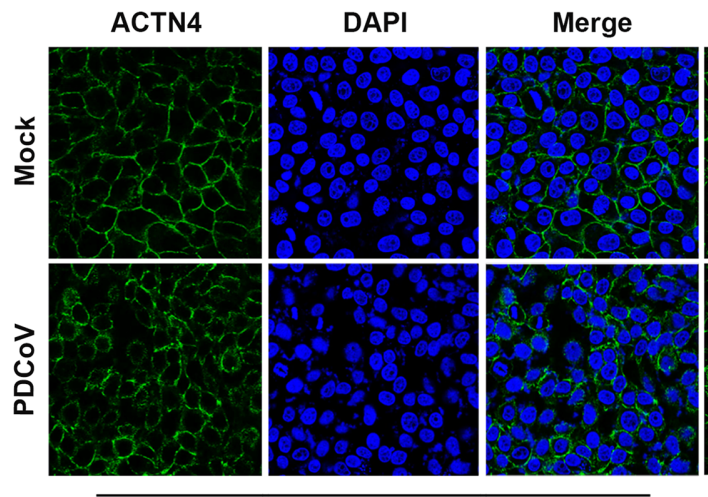

Mock or PDCoV-infected (6 hpi)
B

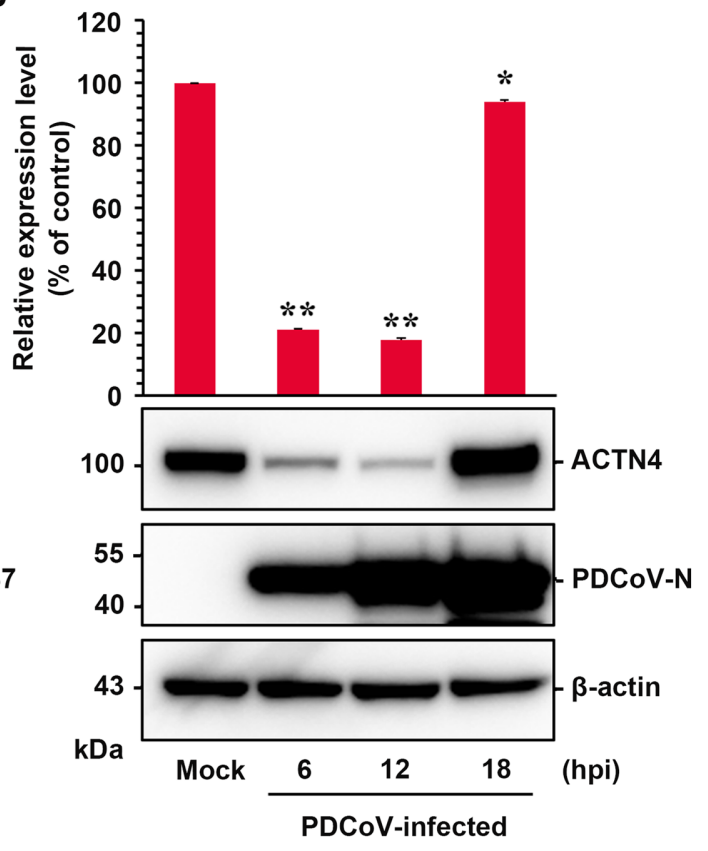

ACTN4

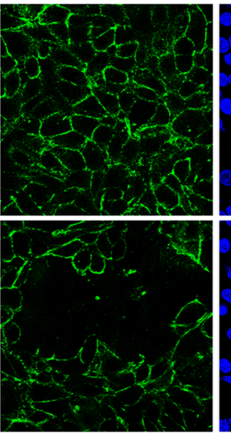

DAPI

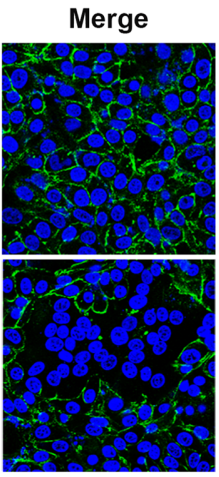

Mock or PDCoV-infected (12 hpi)

Fig. 5. Differential expression of $\alpha$-actinin-4 (ACTN4) in cells expressing NS7 or infected with PDCoV.

(A and B) Western blot analysis for ACTN4. Cell lysates were prepared from PDCoV NS7 gene-expressing PK cells (A) or PDCoV-infected ST cells (B) at the time points indicated and immunoblotted to determine the expression profile of ACTN4 with anti-ACTN4 antibody (top panels). The blots were also reacted with anti-His tag or anti-PDCoV N (middle panels) and anti- $\beta$-actin (bottom panels) antibodies to confirm the status of NS7 expression or PDCoV infection and equal protein loading, respectively. ACTN4 expression was quantitatively analyzed using densitometry in terms of the relative density value to the $\beta$-actin gene and PK-PDCoV-NS7 or PDCoV-infected sample results were compared to PK-control or mock-infected results, respectively. Values are representative of the mean from three independent experiments and error bars denote the mean \pm SDM. ${ }^{*} p=0.001$ to $0.05 ;{ }^{* *} p<0.001$. (C) Immunofluorescent detection of ACTN4. At the time points indicated, mock-infected (upper panels) or PDCoV-infected (lower panels) ST cells were subjected to IFA with an anti-ACTN4 antibody, followed by DAPI counterstaining and examination under a fluorescence microscope at 200× magnification.

coronaviruses has been produced [20-26]. However, the NS7 protein, which is one of the PDCoV accessory genes, is yet to be investigated. In this work we generated a porcine cell line stably expressing the NS7 protein and further used it to profile global protein abundance changes in host cells in response to NS7 using a proteomic approach.

We initially used online software programs including TargetP 1.1 Server (http://www.cbs.dtu.dk/services/ TargetP/), CELLO v.2.5: subCELlular LOcalization predictor (http://cello.life.nctu.edu.tw/), and PSORT (http://www. 
genscript.com/psort.html), to predict the cellular localization of viral protein NS7. The results indicated that NS7 is unlikely to be located in the mitochondria. However, subcellular localization analyses showed that NS7 is present in the cytoplasm of PK-PDCoV-NS7 cells, colocalizing predominantly with the mitochondria, but not with the ER, ERGIC or Golgi apparatus. The NS7 protein was present at high concentrations in the mitochondrial fractions of the stably NS7-transfected cells, but at low concentrations in their cytoplasmic fractions. This finding is of interest because the intracellular localization of the two main accessory proteins of PDCoV, NS6 and NS7, differs markedly. NS6 was reported to co-localize mainly with the ER and ERGIC, and partially with the Golgi apparatus [16]. It is known that the ERGIC is the site of coronavirus assembly and packaging [18, 47]. Previous studies have shown that of the PDCoV accessory genes, only NS6 could be detected in purified virions, indicating that NS7 is not a component of PDCoV virions [16, 17]. Although this biological localization in NS7-expressing cells has yet to be confirmed using an authentic NS7 protein in PDCoV-infected cells, the absolutely distinct distributions of NS6 and NS7 within the cytoplasm suggests the possibility that their functions are specialized for PDCoV multiplication, with NS6 playing structural roles in viral assembly and budding events, and NS7 playing non-structural roles contributing to the completion of viral replication.

Our proteomic data revealed that seven cellular proteins are differentially expressed in PDCoV NS7 gene-expressing porcine cells. These proteins are associated with several cellular processes such as protein biosynthesis, metabolism, and cytoskeleton networks. The importance of the functional roles of the selected host proteins affected by the interplay of the PDCoV NS7 protein with the host cell is discussed below. Like many other viruses, coronaviruses modulate host protein translation in order to favor the synthesis of their own gene products, leading to effective virus reproduction. In the present study, the amount of $40 \mathrm{~S}$ ribosomal protein S12, a component of the eukaryotic small ribosomal subunit, was positively affected by the host response to the PDCoV NS7 protein. Therefore, it is conceivable that such differential expression of a ribosomal subunit constituent may be associated with the regulation of both host and viral protein synthesis. In response to environmental stressors, including viral infection, cells reorganize their metabolism to acclimate to stress-mediated injury, which, in turn, may result in the differential production of metabolic enzymes. In this regard, we found significant suppression of CPS1 in cells expressing the PDCoV NS7 protein. CPS1 is a complex multidomain enzyme located in the mitochondrial matrix that plays a paramount role in the urea cycle [48]. Mitochondria are important cellular organelles that participate not only in cell life as the source of energy production, but also in active cell death via the mitochondrial apoptosis pathway [49]. We have previously demonstrated that PDCoV triggers caspase-dependent intrinsic apoptosis by releasing apoptogenic cytochrome $c$ [34]. The present study also showed that viral accessory protein NS7 is a mitochondrialtargeting protein that significantly downregulates the mitochondrial CPS1. Although it is unknown whether CPS1 deficiency is involved in apoptosis, one hypothesis that can explain our results is that the mitochondrial NS7 protein is responsible for $\mathrm{PDCoV}$-induced apoptosis by modulating the expression of metabolism-related enzymes such as CPS1, which in turn adjusts the intracellular milieu for optimal PDCoV infection.

The most noteworthy finding in the present study is that expression of two cytoskeletal proteins that participate primarily in cytoskeleton organization, beta-actin and ACTN4, is significantly reduced by elevation of levels of the NS7 protein of PDCoV. Beta-actin is a major cytoskeletal protein that forms actin filaments or microfilaments. These filaments are involved in numerous cellular processes, including cell shape, movement, division, and signal transduction [50]. ACTN4 is a conserved, abundant, and ubiquitous actin-binding protein belonging to the spectrin superfamily, which modulates a wide range of processes [51-58]. As a component of the cytoskeleton, ACTN4 plays crucial roles in remodeling of the actin cytoskeleton, and in stress fiber formation and stability $[59,60]$. Stress fibers are contractile bundles of actin filaments that span the entire length of the cell and are anchored at both ends at focal adhesions, so actin presents a challenging hurdle to virus entry [61, 62]. However, one of the most striking observations of infected cells is the actin remodeling or reorganization that affects every stage of a viral replication cycle [63-67]. Many viruses have evolved to employ strategies to engage and manipulate actin, in order to gain entry into cells, thereby securing progeny reproduction. Given the biological importance of ACTN4, its downregulation observed in our study suggests that PDCoV manipulates the host cytoskeletal organization, possibly to facilitate the processes of viral infection and replication; the NS7 protein may contribute to this actin remodeling pathway.

Since ACTN4 resides in both the cytoplasm and the nucleus of eukaryotic cells, it has dual roles; the cytoplasmic 
and nuclear functions [68]. The former mainly involves actin filament organization as described above, while the latter takes part in the regulation of gene expression by the activation of various transcription factors, including nuclear factor- $\mathrm{kB}$ (NF- $\mathrm{\kappa B})$. The transcriptional regulatory function is independent of the cytoskeletal functions associated with cytoplasmic actin binding [53, 68-70]. Nuclear factor- $\kappa B$ (NF-KB) is a family of transcription factors that regulate immune responses, cell proliferation, apoptosis, and differentiation, through controlling the synthesis of target genes encoding pro-inflammatory cytokines, chemokines, and adhesion molecules [71, 72]. Thus, it is conceivable that as part of the immune evasion process, $\mathrm{PDCoV}$ may take advantage of suppressing immune-related cytokine and chemokine genes by interfering with the ACTN4-dependent NF- $\mathrm{B}$ pathway to subvert the host antiviral defenses, and the NS7 protein may be involved in this mechanism.

In conclusion, to our knowledge this is the first report of a proteomic analysis of cellular responses to the NS7 accessory protein of PDCoV. Although the definite functions of the proteins that we identified here were not determined, it appears likely that alterations in their expression are involved in virus-host interactions, including actin remodeling, leading to successful PDCoV replication. In future studies, we are planning to investigate the actin proteins which are differentially expressed in cells overexpressing PDCoV NS7 or in cells infected with $\mathrm{PDCoV}$, in order to investigate their precise functions in the replication of PDCoV. Altogether, the data presented here advance our understanding of the molecular mechanisms associated with PDCoV-host interactions, viral replication, and pathogenesis.

\section{Acknowledgments}

The authors thank Ji Hyun Jeon for her help in preparing the manuscript. This research was financially supported by the Ministry of Small and Medium-sized Enterprises (SMEs) and Startups (MSS), Korea, under the "Regional Enterprise linked with National-Innovation-Cluster Development Program (R\&D, P0010011)" supervised by the Korea Institute for Advancement of Technology (KIAT). This research was supported by Kyungpook National University Development Project Research Fund, 2018.

\section{Conflict of Interest}

The authors have no financial conflicts of interest to declare.

\section{References}

1. Woo PC, Lau SK, Lam CS, Lau CC, Tsang AK, Lau JH, et al. 2012. Discovery of seven novel mammalian and avian coronaviruses in the genus deltacoronavirus supports bat coronaviruses as the gene source of alphacoronavirus and betacoronavirus and avian coronaviruses as the gene source of gammacoronavirus and deltacoronavirus. J. Virol. 86: 3995-4008.

2. Li G, Chen Q, Harmon KM, Yoon KJ, Schwartz KJ, Hoogland MJ, et al. 2014. Full-length genome sequence of porcine deltacoronavirus strain USA/IA/2014/8734. Genome Announc. 2: e00278-14.

3. Marthaler D, Jiang Y, Collins J, Rossow K. 2014. Complete genome sequence of strain SDCV/USA/Illinois121/2014, a porcine deltacoronavirus from the United States. Genome Announc. 2: e00218-14.

4. Marthaler D, Raymond L, Jiang Y, Collins J, Rossow K, Rovira A. 2014. Rapid detection, complete genome sequencing, and phylogenetic analysis of porcine deltacoronavirus. Emerg. Infect. Dis. 20: 1347-1350.

5. Wang L, Byrum B, Zhang Y. 2014. Detection and genetic characterization of deltacoronavirus in pigs, Ohio, USA, 2014. Emerg. Infect. Dis. 20: 1227-1230.

6. Chen F, Zhu Y, Wu M, Ku X, Yao L, He Q. 2015. Full-length genome characterization of Chinese porcine deltacoronavirus strain CH/SXD1/2015. Genome Announc. 3: e01284-15.

7. Hu H, Jung K, Vlasova AN, Chepngeno J, Lu Z, Wang Q, et al. 2015. Isolation and characterization of porcine deltacoronavirus from pigs with diarrhea in the United States. J. Clin. Microbiol. 53: 1537-1548.

8. Ma Y, Zhang Y, Liang X, Lou F, Oglesbee M, Krakowka S, et al. 2015. Origin, evolution, and virulence of porcine deltacoronaviruses in the United States. MBio 6: e00064.

9. Jung K, Hu H, Eyerly B, Lu Z, Chepngeno J, Saif LJ. 2015. Pathogenicity of 2 porcine deltacoronavirus strains in gnotobiotic pigs. Emerg. Infect. Dis. 21: 650-654.

10. Lee S. Lee C. 2014. Complete genome characterization of Korean porcine deltacoronavirus strain KOR/KNU14-04/ 2014. Genome Announc. 2: e01191-14.

11. Dong N, Fang L, Zeng S, Sun Q, Chen H, Xiao S. 2015. Porcine deltacoronavirus in mainland China. Emerg. Infect. Dis. 21: 2254-2255.

12. Janetanakit $\mathrm{T}$, Lumyai M, Bunpapong N, Boonyapisitsopa $\mathrm{S}$, Chaiyawong S, Nonthabenjawan N, et al. 2016. Porcine deltacoronavirus, Thailand, 2015. Emerg. Infect. Dis. 2: 757-759.

13. Jang G, Lee KK, Kim SH, Lee C. 2017. Prevalence, complete genome sequencing, and phylogenetic analysis of porcine deltacoronavirus in South Korea, 2014-2016. Transbound. Emerg. Dis. 64: 1364-1370.

14. de Groot RJ, Baker SC, Bari R, Enjuanes L, Gorbalenya AE, Holme KV, et al. 2011. Coronaviridae. pp. 806-828. In King AMQ, Adams MJ, Carstens EB, Lefkowitz EJ (eds.), Virus 
Taxonomy: 9th Report of the International Committee on Taxonomy of Viruses, Elsevier, Oxford.

15. Lai MC, Perlman S, Anderson LJ, 2007. Coronaviridae. pp. 1305-1336. In Knipe DM, Howley PM, Griffin DE, Martin MA, Lamb RA, Roizman B, and Straus SE (eds.), Fields Virology, 5th Ed. Lippincott Williams \& Wilkins, Philadelphia, Pennsylvania.

16. Fang $\mathrm{P}$, Fang L, Liu X, Hong Y, Wang Y, Dong N, et al. 2016. Identification and subcellular localization of porcine deltacoronavirus accessory protein NS6. Virology 499: 170-177.

17. Fang P, Fang L, Hong Y, Liu X, Dong N, Ma P, et al. 2017. Discovery of a novel accessory protein NS7a encoded by porcine deltacoronavirus. J. Gen. Virol. 98: 173-178.

18. McBride R, Fielding BC. 2012. The role of severe acute respiratory syndrome (SARS)-coronavirus accessory proteins in virus pathogenesis. Viruses 4: 2902-2923.

19. Liu DX, Fung TS, Chong KK, Shukla A, Hilgenfeld R. 2014. Accessory proteins of SARS-CoV and other coronaviruses. Antiviral Res. 109: 97-109.

20. de Haan CA, Masters PS, Shen X, Weiss S, Rottier PJ. 2002. The group-specific murine coronavirus genes are not essential, but their deletion, by reverse genetics, is attenuating in the natural host. Virology 296: 177-189.

21. Yount B, Roberts RS, Sims AC, Deming D, Frieman MB, Sparks J, et al. 2005. Severe acute respiratory syndrome coronavirus group-specific open reading frames encode nonessential functions for replication in cell cultures and mice. J. Virol. 79: 14909-14922.

22. Zhang R, Wang K, Ping X, Yu W, Qian Z, Xiong S, et al. 2015. The ns12.9 accessory protein of human coronavirus OC43 is a viroporin involved in virion morphogenesis and pathogenesis. J. Virol. 89: 11383-11395.

23. Menachery VD, Mitchell HD, Cockrell AS, Gralinski LE, Yount BL Jr, Graham RL, et al. 2017. MERS-CoV accessory ORFs play key role for infection and pathogenesis. MBio 8: e00665-17.

24. Niemeyer D, Zillinger T, Muth D, Zielecki F, Horvath G, Suliman T, et al. 2013. Middle East respiratory syndrome coronavirus accessory protein $4 \mathrm{a}$ is a type I interferon antagonist. J. Virol. 87: 2489-2495.

25. Siu KL, Yeung ML, Kok KH, Yuen KS, Kew C, Lui PY, et al. 2014. Middle East respiratory syndrome coronavirus 4a protein is a double-stranded RNA-binding protein that suppresses PACT-induced activation of RIG-I and MDA5 in the innate antiviral response. J. Virol. 88: 4866-4876.

26. Zeng LP, Gao YT, Ge XY, Zhang Q, Peng C, Yang XL, et al. 2016. Bat severe acute respiratory syndrome-like coronavirus WIV1 encodes an extra accessory protein, ORFX, involved in modulation of the host immune response. J. Virol. 90: 6573-6582.

27. Lee S, Lee C. 2015. Functional characterization and proteomic analysis of the nucleocapsid protein of porcine deltacoronavirus. Virus. Res. 208: 136-145.
28. Jang G, Kim SH, Lee YJ, Kim S, Lee DS, Lee KK, et al. 2018. Isolation and characterization of a Korean porcine deltacoronavirus strain KNU16-07. J. Vet. Sci. 19: 586-590.

29. Sambrook J, Russell DW. 2001. Molecular Cloning: A Laboratory Manual, 3rd Ed. Cold Spring Harbor Laboratory Press, Cold Spring Harbor, New York.

30. Creixell P, Schoof EM, Tan CS, Linding R. 2012. Mutational properties of amino acid residues: implications for evolvability of phosphorylatable residues. Philos. Trans. R. Soc. Lond. B. Biol. Sci. 367: 2584-2593.

31. Lee YJ, Park CK, Nam E, Kim SH, Lee OS, Lee D, et al. 2010. Generation of a porcine alveolar macrophage cell line for the growth of porcine reproductive and respiratory syndrome virus. J. Virol. Methods 163: 410-415.

32. Nam E, Lee C. 2010. Contribution of the porcine aminopeptidase $\mathrm{N}(\mathrm{CD} 13)$ receptor density to porcine epidemic diarrhea virus infection. Vet. Microbiol. 144: 41-50.

33. Oh J, Lee C. 2012. Proteomic characterization of a novel structural protein ORF5a of porcine reproductive and respiratory syndrome virus. Virus Res. 169: 255-263.

34. Lee YJ, Lee C. 2018. Porcine deltacoronavirus induces caspase-dependent apoptosis through activation of the cytochrome c-mediated intrinsic mitochondrial pathway. Virus Res. 253: 112-123.

35. Oakley BR, Kirsch DR, Morris NR. 1980. A simplified ultrasensitive silver stain for detecting proteins in polyacrylamide gels. Anal. Biochem. 105: 361-363.

36. Shevchenko A, Wil M, Vorm O, Mann M. 1996. Mass spectrometric sequencing of proteins silver-stained polyacrylamide gels. Anal. Chem. 68: 850-858.

37. Fernandez J, Gharahdaghi F, Mische SM. 1998. Routine identification of proteins from sodium dodecyl sulfatepolyacrylamide gel electrophoresis (SDS-PAGE) gels or polyvinyl difluoride membranes using matrix assisted laser desorption/ionization-time of flight-mass spectrometry (MALDI-TOF-MS). Electrophoresis 19: 1036-1045.

38. Sagong M, Lee C. 2011. Porcine reproductive and respiratory syndrome virus nucleocapsid protein modulates interferon- $\beta$ production by inhibiting IRF3 activation in immortalized porcine alveolar macrophages. Arch. Virol. 156: 2187-2195.

39. Livak KJ, Schmittgen TD. 2001. Analysis of relative gene expression data using real-time quantitative PCR and the 2(-Delta Delta C(T)) Method. Methods 25: 402-408.

40. Zhang H, Guo X, Ge X, Chen Y, Sun Q, Yang H. 2009. Changes in the cellular proteins of pulmonary alveolar macrophage infected with porcine reproductive and respiratory syndrome virus by proteomics analysis. J. Proteome. Res. 8: 3091-3097.

41. Alfonso P, Rivera J, Hernáez B, Alonso C, Escriban JM. 2004. Identification of cellular proteins modified in response to African swine fever virus infection by proteomics. Proteomics 4: 2037-2046.

42. Brasier AR, Spratt H, Wu Z, Boldogh I, Zhang Y, Garofalo $R P$, et al. 2004. Nuclear heat shock response and novel 
nuclear domain 10 reorganization in respiratory syncytial virus-infected A549 cells identified by high-resolution twodimensional gel electrophoresis. J. Virol. 78: 11461-11476.

43. Neuman BW, Joseph JS, Saikatendu KS, Serrano P, Chatterjee A, Johnson MA, et al. 2008. Proteomics analysis unravels the functional repertoire of coronavirus nonstructural protein 3. J. Virol. 82: 5279-5294.

44. Ringrose JH, Jeeninga RE, Berkhout B, Speijer D. 2008. Proteomic studies reveal coordinated changes in T-cell expression patterns upon infection with human immunodeficiency virus type 1. J. Virol. 82: 4320-4330.

45. Sagong M, Lee C. 2010. Differential cellular protein expression in continuous porcine alveolar macrophages regulated by the porcine reproductive and respiratory syndrome virus nucleocapsid protein. Virus Res. 151: 88-96.

46. Zhang J, Li D, Zheng Y, Cui Y, Feng K, Zhou J, et al. 2008. Proteomic profiling of hepatitis B virus-related hepatocellular carcinoma in China: a SELDI-TOF-MS study. Int. J. Clin. Exp. Pathol. 1: 352-361.

47. McBride R, van Zyl M, Fielding BC. 2014. The coronavirus nucleocapsid is a multifunctional protein. Viruses 6: 2991-3018.

48. Martínez AI, Pérez-Arellano I, Pekkala S, Barcelona B, Cervera J. 2010. Genetic, structural and biochemical basis of carbamoyl phosphate synthetase 1 deficiency. Mol. Genet. Metab. 101: 311-323.

49. Mignotte B, Vayssiere JL. 1998. Mitochondria and apoptosis. Eur. J. Biochem. 252: 1-15.

50. Winder SJ, Ayscough KR. 2005. Actin-binding proteins. J. Cell Sci. 118: 651-654.

51. An HT, Yoo S, Ko J. 2016. $\alpha$-actinin-4 induces the epithelialto-mesenchymal transition and tumorigenesis via regulation of snail expression and $\beta$-catenin stabilization in cervical cancer. Oncogene 35: 5893-5904.

52. Agarwal N, Adhikari AS, Iyer SV, Hekmatdoost K, Welch DR, Iwakuma T. 2013. MTBP suppresses cell migration and filopodia formation by inhibiting ACTN4. Oncogene 32: 462470.

53. Aksenova V, Turoverova L, Khotin M, Magnusson KE, Tulchinsky E, Melino G, et al. 2013. Actin-binding protein alpha-actinin 4 (ACTN4) is a transcriptional co-activator of RelA/p65 sub-unit of NF-kB. Oncotarget 4: 362-372.

54. Honda K, Yamada T, Endo R, Ino $Y$, Gotoh M, Tsuda H, et al. 1998. Actinin-4, a novel actin-bundling protein associated with cell motility and cancer invasion. J. Cell Biol. 140: 13831393.

55. Khurana S, Chakraborty S, Cheng X, Su YT, Kao HY. 2011. The actin-binding protein, actinin alpha 4 (ACTN4), is a nuclear receptor coactivator that promotes proliferation of MCF-7 breast cancer cells. J. Biol. Chem. 286: 1850-1859.

56. Kumeta M, Yoshimura SH, Harata M, Takeyasu K. 2010. Molecular mechanisms underlying nucleocytoplasmic shuttling of actinin-4. J. Cell Sci. 123: 1020-1030.

57. Sharma S, Mayank AK, Nailwal H, Tripathi S, Patel JR, Bowzard JB, et al. 2014. Influenza A viral nucleoprotein interacts with cytoskeleton scaffolding protein $\alpha$-actinin- 4 for viral replication. FEBS J. 281: 2899-2914.

58. Zhao X, Khurana S, Charkraborty S, Tian Y, Sedor JR, Bruggman LA, et al. 2016. $\alpha$-actinin 4 (ACTN4) regulates glucocorticoid receptor-mediated transactivation and transrepression in podocytes. J. Biol. Chem. 292: 1637-1647.

59. Gross SR. 2013. Actin binding proteins: their ups and downs in metastatic life. Cell Adh. Migr. 7: 199-213.

60. Kemp JP Jr, Brieher WM. 2018. The actin filament bundling protein $\alpha$-actinin- 4 actually suppresses actin stress fibers by permitting actin turnover. J. Biol. Chem. 293: 14520-14533.

61. Burridge K, Guilluy C. 2016. Focal adhesions, stress fibers and mechanical tension. Exp. Cell Res. 343: 14-20.

62. Pellegrin S, Mellor H. 2007. Actin stress fibres. J. Cell Sci. 120: 3491-3499.

63. Berkova Z, Crawford SE, Blutt SE, Morris AP, Estes MK. 2007. Expression of rotavirus NSP4 alters the actin network organization through the actin remodeling protein cofilin. J. Virol. 81: 3545-3553.

64. Taylor MP, Koyuncu OO, Enquist LW. 2011. Subversion of the actin cytoskeleton during viral infection. Nat. Rev. Microbiol. 9: 427-439.

65. Lv X, Li Z, Guan J, Hu S, Zhang J, Lan Y, et al. 2019. Porcine hemagglutinating encephalomyelitis virus activation of the integrin $\alpha 5 \beta 1$-FAK-cofilin pathway causes cytoskeletal rearrangement to promote its invasion of N2a Cells. J. Virol. 93: e01736-18.

66. Stradal TEB, Schelhaas M. 2018. Actin dynamics in hostpathogen interaction. FEBS Lett. 592: 3658-3669.

67. Surjit M, Liu B, Jameel S, Chow VT, Lal SK. 2004. The SARS coronavirus nucleocapsid protein induces actin reorganization and apoptosis in COS-1 cells in the absence of growth factors. Biochem. J. 383: 13-18.

68. Lomert E, Turoverova L, Kriger D, Aksenov ND, Nikotina AD, Petukhov A, et al. 2018. Co-expression of RelA/p65 and ACTN4 induces apoptosis in non-small lung carcinoma cells. Cell Cycle 17: 616-626.

69. Huang Q, Li X, Huang Z, Yu F, Wang X, Wang S, et al. 2019. ACTN4 promotes the proliferation, migration, metastasis of osteosarcoma and enhances its invasive ability through the NF-кB pathway. Pathol. Oncol. Res. doi: 10.1007/s12253019-00637.

70. Zhao X, Hsu KS, Lim JH, Bruggeman LA, Kao HY. 2015. $\alpha$-Actinin 4 potentiates nuclear factor $\kappa$-light-chain-enhancer

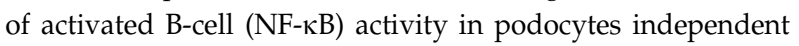
of its cytoplasmic actin binding function. J. Biol. Chem. 290: 338-349.

71. Oeckinghaus A, Ghosh S, 2009. The NF-kappaB family of transcription factors and its regulation. Cold Spring Harb. Perspect. Biol. 1: a000034.

72. Tornatore L, Thotakura AK, Bennett J, Moretti M, Franzoso G. 2012. The nuclear factor kappa B signaling pathway: integrating metabolism with inflammation. Trends Cell Biol. 22: $557-566$. 